\title{
MIGRAÇÃO E CONTRATAÇÃO DE TRABALHADORES INDÍGENAS EMPREGADOS PELA ECONOMIA DO AGRONEGÓCIO
}

\author{
Graziela da Silva Motta ${ }^{1}$
}

\section{Introdução}

Este artigo tem como objetivo analisar as migrações de assalariados indígenas que trabalham temporariamente nas colheitas de maçã no Sul do país, especificamente no município de Vacaria/RS, com o intuito de compreender como elas estão atreladas à produção de capital por meio da economia do agronegócio. Trata-se da observação de um fenômeno complexo e relativamente recente, que conduziu os trabalhadores indígenas ao mundo do trabalho assalariado ao longo das duas primeiras décadas do século XXI. Dessa maneira, este artigo propõe descortinar parte desse processo produtivo a partir do fenômeno da migração de trabalhadores indígenas aos pomares de maçã no Sul do Brasil.

Atualmente, a produção nacional de maçãs em escala comercial está concentrada em poucos municípios localizados nos estados de Santa Catarina e Rio Grande do Sul, onde o fluxo de trabalhadores migrantes aumenta no período de safra. Dentre esses municípios produtores, destaca-se Vacaria/RS como um dos principais, onde foi desenvolvida parte do trabalho de campo desta investigação. Além de Vacaria, outros municípios foram visitados, locais de origem dos trabalhadores indígenas empregados no período da safra da fruta ${ }^{2}$. Esses trabalhadores, em sua maioria, são homens oriundos de terras indígenas localizadas no interior dos estados do Mato Grosso do Sul e do Rio Grande do Sul. Comumente, os trabalhadores indígenas são organizados e buscados pelos intermediários dos produtores de maçã em seu local de origem, permanecendo nos alojamentos dos pomares de Vacaria do final do mês de janeiro a meados do mês de março, a fim de colher a variedade de maçã denominada Gala. Os homens viajam individualmente, separando-se do seu grupo familiar durante o período de trabalho. Ao final da safra, os trabalhadores retornam ao seu local de origem. As despesas de

\footnotetext{
${ }^{1}$ Instituto Federal de Educação, Ciência e Tecnologia Farroupilha, Campus Frederico Westphalen, Brasil. Email: grazielasm13@gmail.com

ORCID id: https://orcid.org/0000-0002-4068-5687

${ }^{2} \mathrm{O}$ local de origem desses trabalhadores indígenas não será revelado a fím de proteger a identidade étnica desses trabalhadores.
} 
deslocamento são custeadas pelos produtores, que são responsáveis pelo retorno desses trabalhadores a qualquer tempo. Esse processo de organização dos trabalhadores pelos intermediários da relação capital/trabalho será mais bem desenvolvido ao longo do texto.

Comparativamente à produção de grãos, a fruticultura é muito mais dependente de força de trabalho humano, especialmente no período de colheita. Tal aspecto movimenta a geração de empregos formais pelo modelo de economia baseada no agronegócio. No entanto, o emprego, que é formalizado, assume aspectos de precarização desde a reestruturação produtiva do agronegócio, que está prestes a completar 20 anos. Um dos aspectos referentes à precarização é a sazonalidade do emprego, que não garante a reprodução social dos sujeitos fora do trabalho.

O que possibilita essa relação específica que envolve capital e trabalho entre os produtores de maçã e os trabalhadores indígenas reside no tipo de migração/deslocamento que ocorre. Essa forma de migração de trabalhadores indígenas possui especificidades em relação aos tipos de migração mais comuns, discutidos pela literatura sócioantropológica (Menezes, 2002; Bendini, Steimbreger e Radonich, 2011), principalmente por incluir normas jurídicas que derivaram dos tensionamentos entre patrão, empregado e uma série de intermediários, que serão mais bem apresentados ao longo do artigo.

\section{Metodologia}

Para a realização desta pesquisa foi necessário adotar uma abordagem qualitativa, uma vez que somente os dados estatísticos não seriam suficientes para atingir o objetivo da investigação. Ao mesmo tempo, houve um diálogo interdisciplinar e necessário entre as ciências sociais, sobretudo entre a sociologia e a antropologia.

A produção de capital pela economia do agronegócio está expressa em diversas estatísticas, como demonstram os Censos Agropecuários. O aumento da produtividade, a quantidade de agrotóxicos consumidos pelas lavouras e o número de estabelecimentos produtores também estão expressos em números pelo Instituto Brasileiro de Geografia e Estatística. No entanto, as condições sob as quais os trabalhadores se encontram para 
que esse capital seja produzido só podem ser apresentadas por meio de um olhar mais aproximado do pesquisador em relação ao objeto de estudo.

No caso desta pesquisa, procurei compreender como aconteciam os deslocamentos dos trabalhadores indígenas dentro do cenário de produção de maçãs em Vacaria. Para tanto, precisei encontrar pessoas bem informadas dentro desse universo, que pudessem me fornecer informações, mesmo que exploratórias. Ao todo, 49 pessoas foram entrevistadas. Dentre elas, encontram-se produtores de maçãs, intermediários da relação capital/trabalho (como os empreiteiros e os recrutadores), servidores públicos políticos, servidores da segurança pública do município de Vacaria, representantes de sindicatos de trabalhadores rurais de dois municípios, representantes da Fundação Nacional do Índio de diversos municípios, representantes do Conselho Indigenista Missionário, funcionários permanentes de empresas produtoras de maçã, caciques, lideranças indígenas, trabalhadores indígenas e não indígenas.

Esse trabalho de campo, para o qual precisei me deslocar para o Mato Grosso do Sul e diversos municípios do Rio Grande do Sul, foi iniciado em 2017, no município de Vacaria, estendendo-se para outros municípios, reservas e terras indígenas ao longo do ano de 2018. Em Vacaria, além das entrevistas, pude visitar os parques de industrialização que classificam as maçãs em categorias de qualidade, bem como os pomares - de uma maneira bem limitada pelos produtores. Embora fique evidente que se trata de um objeto de investigação que ocupa diversos espaços ao mesmo tempo, o meu deslocamento também se deu em virtude da impossibilidade de conversar com os trabalhadores indígenas dentro dos espaços de trabalho. No pomar, o que eu poderia saber estava atrelado ao quanto de informação os produtores estavam dispostos a me fornecer. Além disso, alguns alojamentos também controlavam o tempo de não trabalho dos indígenas a fim de garantir o descanso que possibilita a colheita no dia seguinte.

Desse modo, o método escolhido para a geração de dados é conhecido como Snowball Sampling, Amostragem em Cadeia por Referência ou Amostra em Bola de Neve (Biernacki e Waldorf, 1981; Vinuto, 2014). Esse método gera uma rede de indivíduos bem informados sobre aspectos específicos a serem investigados e que são difíceis de localizar. Essa rede é tecida por meio de indicações desses sujeitos. Um exemplo da utilização deste método pode ser encontrado nos estudos de Becker (2008) sobre sociologia do desvio, pois o autor inicia a rede de entrevistados a partir de conhecidos do seu meio social para chegar àqueles que aceitariam conversar sobre um assunto estigmatizante. 
Com efeito, esse método foi de extrema importância, pois permitiu a localização de trabalhadores indígenas em seu local de origem, entre outros sujeitos importantes para descortinar aspectos desta pesquisa. Conforme a rede de interlocutores se formava, as entrevistas eram realizadas. Além das indicações de interlocutores, houve, também, sugestões sobre pessoas com quem não conversar a fim de me proteger. Um exemplo disso aconteceu no Mato Grosso do Sul quando um entrevistado começou a citar nomes de pessoas essenciais para a pesquisa, ao passo que alertava que elas poderiam me prejudicar. Desse modo, realizei diversas modalidades de entrevistas, como semiestruturadas, discursivas e informais (Cardano, 2017; Gil, 2008), com a finalidade de adequar as questões ao perfil dos interlocutores.

Os documentos sem tratamento analítico também foram fontes de dados, como fotografias, notícias veiculadas em jornais, documentos públicos de instituições do Estado, formulários, legislação, entre outros. O uso de documentos em pesquisa social é mais uma forma de permitir a triangulação dos dados gerados na pesquisa, o que torna mais fidedigna a análise dos dados (Gil, 2008).

Além das entrevistas e dos documentos, destaco os dados estatísticos gerados por instituições de pesquisa como o Instituto Brasileiro de Geografia e Estatística e a Food and Agriculture Organization of the United Nations, que também compõem esta pesquisa. Esses dados foram utilizados principalmente para a compreensão do fenômeno produtivo de maçãs em escala local, nacional e global.

\section{Maçãs no agronegócio}

Polanyi (2000) entende que as relações de mercado tornaram a sociedade um apêndice do sistema econômico, porque se tornou dominante em escala global. Porém, não se trata de relações naturais, mas, sim, de relações de mercado construídas e propagadas pelo Estado. Assim, é necessário compreender as políticas que deram impulso à economia do agronegócio já estabelecido como uma agricultura convencional no país.

As políticas que gestaram o agronegócio são conhecidas por incentivar uma “modernização 'conservadora' da agricultura” (Delgado, 2012). Elas foram criadas no regime militar e estavam focadas no aumento da produção e da produtividade agrícola. Seu aspecto aparentemente contraditório às intenções de modernização, ou seja, seu 
sentido conservador reside no fato de que se manteve intocada a estrutura agrária, formada por grandes propriedades de terra (Delgado, 2012, 2017).

As políticas adotadas pelo Estado para colocar em prática o projeto de agricultura moderna foram as pertencentes ao pacote tecnológico da Revolução Verde. Basicamente, financiava-se a aquisição de maquinários no campo, a comercialização de sementes geneticamente modificadas que se adaptariam às máquinas e à utilização de produtos como agrotóxicos e insumos.

Diversas políticas foram criadas para impulsionar essas mudanças no cenário rural brasileiro, tais como i) a política de créditos agrícolas, capaz de cobrir os custos de implantação do novo modelo produtivo; ii) incentivos fiscais, para estimular a produção de certas culturas, entre outras. De acordo com Taylor e Rioux,

O objetivo da intensificação agrícola tem sido fortemente promovido em todo o sul global. A partir da década de 1960, tanto o governo dos EUA como instituições internacionais de desenvolvimento, como o Banco Mundial, procuraram difundir proativamente o que é comumente conhecido como tecnologias da Revolução Verde em todas as regiões pós-coloniais. Essa abordagem para modernizar a agricultura envolveu três principais componentes baseados na experiência dos EUA. Em primeiro lugar, ele se concentrou no uso de sementes de variedades de alto rendimento (SAR) produzidas por cientistas que cruzaram tipos de plantas existentes para desenvolver híbridos que seriam mais fortes e mais produtivos. Em segundo lugar, essas sementes de alto rendimento deveriam ser combinadas com o uso generalizado de fertilizantes sintéticos e pesticidas para garantir seu potencial para produzir rendimentos mais altos. Finalmente, uma modernização tecnológica mais ampla da agricultura foi vista como um terceiro pilar do modelo, no qual a mecanização e a irrigação mais avançadas poderiam facilitar as economias de escala que acentuariam ainda mais os rendimentos agregados (Taylor e Rioux, 2018: 108. Tradução própria) $)^{3}$.

A concessão de créditos pelo governo foi diminuindo desde a década de 1980, conduzindo a economia a uma grave crise fiscal em 1982. Além dessa crise, a Constituição de 1988 ajudou a cessar as ações de modernização conservadora da agricultura. Para superar esse momento conturbado da economia brasileira, os governos seguintes ao regime militar apostaram no mercado de exportações de produtos primários

\footnotetext{
${ }^{3}$ The goal of agricultural intensification has indeed been heavily promoted throughout the global South. From the 1960s onwards, both the US government and international development institutions such as the World Bank sought to proactively diffuse what are commonly known as Green Revolution technologies across postcolonial regions. This approach to modernizing agriculture involved three chief components based on the US experience. First, it pivoted on the use of high-yield variety (HYV) seeds produced by scientists who interbred existing plants types to develop hybrids that would be stronger and more productive. Second, these HYN seeds were to be combined with the widespread use of synthetic fertilizers and pesticides to lock in their potential to deliver higher yields. Finally, a broader technological upgrading of agriculture was seen as a third pillar of the model wherein mechanization and more advanced irrigation could facilitate the economies of scale that would accentuate aggregate yields still further.
} 
e agroprocessados (commodities), aproveitando a estrutura de cadeias agroindustriais já existente (Delgado, 2012).

Conforme Delgado (2012), nos governos de Fernando Henrique Cardoso, foi possível vivenciar algum conforto econômico, uma vez que foram governos dedicados às privatizações de estatais. No entanto, isso conduziu a outra crise fiscal no ano de 1999. As alternativas escolhidas para superar esta nova crise foram as mesmas que superaram a crise anterior (de 1982): estimular novamente a exportação de commodities. Essas políticas marcaram um momento de reestruturação produtiva conhecida por agronegócio. Atualmente, Acosta e Brand (2018) reconhecem a inclinação neoextrativista do agronegócio. No Brasil, o minério de ferro, o petróleo e as commodities são responsáveis pela manutenção de uma economia altamente dependente de recursos naturais.

Nesse contexto, os grãos, como o milho e a soja, são mais notáveis em termos quantitativos. No caso da soja, a produção nacional saiu de 1,9 milhões de toneladas em 1970 para atingir o marco de 46,1 milhões de toneladas em 2006 (SIDRA IBGE, 2019). De forma análoga, no caso da produção de frutas frescas, especificamente da maçã, toda essa reestruturação produtiva permitiu o aumento de 30,7 mil toneladas de maçã em 1972 para 1,3 milhões de toneladas em 2017 (IBGE Cidades, 2019).

Embora grãos e frutas frescas utilizem o modelo de economia baseada no agronegócio, elas resguardam formas de produção específicas. No caso dos grãos, a produção conta com a mecanização no plantio e na colheita, bem como com a transformação da matéria prima em outros produtos. Já na produção de frutas, especialmente de maçãs, o processo industrial não transforma a fruta em outros produtos. O valor da mercadoria "maçã” está em sua versão in natura, ou seja, interessa ao mercado a fruta sem danos, de coloração intensa, entre outros aspectos. Isso significa dizer que o parque de industrialização de maçãs está organizado de maneira a separar as frutas em categorias de qualidade para depois destiná-las ao mercado.

A submissão das atividades da agricultura aos processos da indústria é o que resume o termo agribusiness, desenvolvido por Davis e Goldberg em 1957. Para esses autores, agribusiness significa "a soma de todas as operações envolvidas na fabricação e distribuição de suprimentos agrícolas; operações de produção na fazenda; e o armazenamento, processamento e distribuição de produtos agrícolas e itens feitos a partir deles” (1957: 2 - tradução própria). No Brasil, a economia do agronegócio foi 
gestada no período da "modernização 'conservadora' da agricultura" (Delgado, 2012) e fortalecida pelo Estado no início do século XXI.

Nesse contexto, a produção de grãos consegue mecanizar quase que por completo as principais fases da sua cadeia produtiva, como o plantio e a colheita, enquanto que a cadeia produtiva de frutas, especialmente a de maçãs, necessita de mão de obra, principalmente no período de safra. Conforme Graziano Silva (1981), a fase de uma produção agrícola mais difícil de mecanizar é a da colheita, principalmente de frutas frescas. Se isso foi uma dificuldade para os produtores na década de 70, permaneceu também no início do século XXI, evidenciando a impossibilidade de a agricultura ser um braço da indústria e de as máquinas substituírem o trabalho humano.

A produção de maçã evidencia essa situação, pois nem as mudanças genéticas nem os produtos agrotóxicos conseguiram controlar a agricultura por completo e eliminar a dependência da força de trabalho ${ }^{4}$. No que diz respeito aos trabalhadores, as maçãs não podem ser batidas umas nas outras, devem ser colhidas com o pedúnculo ${ }^{5}$ e o prazo estabelecido pela própria cultivar deve ser respeitado. As maçãs caídas do pé, batidas ou sem pedúnculo serão destinadas à indústria de sucos e derivados, onde, muitas vezes, o custo do trabalho de recolhimento dessas frutas não compensa para os bolsos do produtor.

Por conta das características fisiológicas do fruto, a força de trabalho necessária para a colheita da maçã deve estar muito bem organizada em um mercado de trabalho. Isso significa dizer que os trabalhadores devem estar à disposição dos produtores assim que se iniciar a safra. Ainda, trata-se de um quantitativo de trabalhadores muito alto em um curto espaço de tempo, que aceita trabalhar sob condições climáticas adversas. Por conta disso, perfis de trabalhadores são preferidos para executar essas exigências produtivas. Dessa maneira, este texto trará elementos para pensar sobre a contratação de trabalhadores indígenas: o perfil cultural dos trabalhadores que contribui para a reprodução de capital ou seria a produção de capital que contribui para a reprodução social dos trabalhadores indígenas?

\footnotetext{
${ }^{4}$ É muito comum a utilização de "reguladores de crescimento" quando há atrasos na colheita da Gala. Trata-se de um produto agrotóxico que diminui a velocidade da maturação da fruta. Além disso, existem máquinas com inteligência artificial que já foram testadas em pomares da França, porém muitas delas não conseguiram evitar o dano mecânico.

${ }^{5} \mathrm{O}$ pedúnculo é o pequeno cabo que liga a maçã à macieira. No momento da colheita, deverá estar presente na maçã, pois é o pedúnculo que contribui para a durabilidade do fruto nas câmaras frigoríficas durante seu período de armazenamento.
} 


\section{Maçãs em números}

No mundo, a China lidera o ranking dos países produtores de maçãs, com uma produção que girou em torno de 41 milhões de toneladas em 2017. No mesmo ano, o Brasil atingiu 1,3 milhão de toneladas da fruta, ocupando o $11^{\circ}$ lugar no ranking, algo em torno de $1,5 \%$ da produção mundial (FAO, 2019). A tabela a seguir demonstra os principais países produtores

\begin{tabular}{|c|c|c|c|c|c|c|c|c|c|c|c|c|}
\hline & País & 2007 & 2008 & 2009 & 2010 & 2011 & 2012 & 2013 & 2014 & 2015 & 2016 & 2017 \\
\hline $1^{\circ}$ & China & 27,8 & 29,8 & 31,6 & 33,2 & 35,9 & 38,4 & 39,6 & 40,9 & 38,9 & 40,4 & 41,4 \\
\hline $2^{\circ}$ & EUA & 4,1 & 4,3 & 4,4 & 4,2 & 4,2 & 4,1 & 4,7 & 5,1 & 4,5 & 5,2 & 5,2 \\
\hline $3^{\circ}$ & Turquia & 2,4 & 2,5 & 2,7 & 2,6 & 2,6 & 2,8 & 3,1 & 2,4 & 2,5 & 2,9 & 3 \\
\hline $4^{\circ}$ & Polônia & 1,03 & 2,8 & 2,6 & 1,8 & 2,4 & 2,8 & 3,08 & 3,1 & 3,2 & 3,6 & 2,4 \\
\hline $5^{\circ}$ & Índia & 1,6 & 2 & 1,9 & 1,7 & 2,8 & 2,2 & 1,9 & 2,4 & 2,1 & 2,5 & 2,3 \\
\hline $6^{\circ}$ & Irã & 2,6 & 2,7 & 2 & 1,6 & 1,8 & 1,9 & 1,6 & 1,5 & 2,4 & 2,5 & 2 \\
\hline $7^{\circ}$ & Itália & 2,2 & 2,2 & 2,3 & 2,2 & 2,4 & 1,9 & 2,2 & 2,4 & 2,5 & 2,5 & 1,9 \\
\hline $8^{\circ}$ & Chile & 1,4 & 1,5 & 1,3 & 1,6 & 1,5 & 1,6 & 1,7 & 1,7 & 1,7 & 1,7 & 1,8 \\
\hline $9^{\circ}$ & França & 2,1 & 1,7 & 1,8 & 1,7 & 1,8 & 1,3 & 1,7 & 1,5 & 1,9 & 1,8 & 1,7 \\
\hline $10^{\circ}$ & Rússia & 2,3 & 1,1 & 1,4 & 0,9 & 1,1 & 1,4 & 1,5 & 1,6 & 1,6 & 1,8 & 1,6 \\
\hline $11^{\circ}$ & Brasil & 1,1 & 1,1 & 1,2 & 1,2 & 1,3 & 1,3 & 1,2 & 1,3 & 1,2 & 1 & 1,3 \\
\hline $12^{\circ}$ & Ucrânia & 0,7 & 0,7 & 0,8 & 0,8 & 0,9 & 1,1 & 1,2 & 1 & 1,2 & 1,1 & 1,1 \\
\hline $13^{\circ}$ & Argentina & 1 & 0,9 & 0,9 & 1 & 1 & 0,9 & 0,9 & 1 & 1 & 1 & 1 \\
\hline $14^{\circ}$ & Alemanha & 1,07 & 1 & 1 & 0,8 & 0,8 & 0,9 & 0,8 & 1,1 & 1 & 1 & 0,6 \\
\hline & Total & 51,4 & 54,3 & 55,9 & 55,3 & 60,5 & 62,6 & 65,2 & 67 & 65,7 & 69 & 67,3 \\
\hline
\end{tabular}

Tabela 1: Relação dos principais países produtores de maçã em milhões de toneladas, FAO, 2019.

Comparativamente, a produção de maçãs do Brasil e da China possui diferenças consideráveis. Uma delas é que a produtividade - ou rendimento de quilos por hectares - do Brasil é o dobro do que a da China e muito próxima da produtividade dos Estados Unidos. Porém, quando se trata de maçãs, a quantidade é menos relevante do que a qualidade da fruta do ponto de vista da produção de capital.

A maçã enquanto mercadoria é valiosa em sua versão in natura, ou seja, o capital em potencial nas maçãs está no tamanho da fruta, na sua coloração intensa, na sua durabilidade e no seu sabor. Dificilmente essas características conseguem ser realçadas quando a preocupação do produtor está na produção em massa. As qualidades de mercado estão restritas aos pomares menores, de pequenos produtores, que acabam 
vendendo sua produção aos grandes empresários do ramo. Mesmo assim, existem propriedades de tamanhos variados, que vão de 3 mil a 30 hectares, bem como diferentes mercados explorados, que não será possível apresentar neste texto por conta de sua extensão.

No Brasil, a produção de maçãs foi impulsionada com a "modernização 'conservadora' da agricultura”, gestada no regime militar na década de 1960 (Delgado, 2012). Antes de 1960, a produção de maçãs estava restrita aos espaços domésticos. De certo modo, a pomicultura, pensada em escala comercial, inicia-se com grupos privados e estrangeiros, mas tem seu financiamento essencialmente público desde o regime militar, que criou políticas de expansão da produção e da produtividade em diversos setores da agricultura, sem alterações da estrutura agrária, como mencionei anteriormente.

Os investimentos públicos na pomicultura brasileira aconteceram, principalmente, por meio das leis de incentivos fiscais no regime militar em 1966. A Lei $5.106 / 1966$, que versa sobre incentivos fiscais concedidos a empreendimentos florestais, abatia $50 \%$ do imposto de renda de pessoas físicas e jurídicas que realizassem atividades de reflorestamento. Conforme Mazon e Silva (2017), Willy Frey-membro da família fundadora de Fraiburgo/SC, político e, também, sócio de um grupo francês que instalou um pomar experimental naquele município, onde se descobriu o potencial produtivo da maçã - foi responsável por conseguir incluir a macieira como árvore de reflorestamento na lei de incentivos fiscais para reflorestamento. Em 1966, Willy Frey criou uma empresa de reflorestamento por meio das macieiras e dos pinus com a finalidade de obter o financiamento público na produção de maçãs e de madeiras (Klanovicz, 2007).

Desta maneira, conforme Mazon e Silva (2017), Willy Frey iniciou a implantação dos 100 primeiros hectares de pomares de maçãs com financiamento do Estado. Já na década de 1970, diversos empresários de setores já consolidados na indústria passaram a se dedicar à produção de maçãs em regiões onde o clima propiciava esse cultivo. Outros municípios do Sul do Brasil, como São Joaquim/SC e Vacaria/RS, tornaram-se os principais produtores da fruta em escala nacional.

\section{Os empregos gerados pela produção de maçã}


A cadeia produtiva da maçã pode ser compreendida em sua produção no pomar e em sua produção no processamento industrial. Ambos espaços geram tipos de empregos que se conformam com o ritmo do processo produtivo. No pomar, poucas pessoas são contratadas para serviços permanentes. Nas atividades de raleio ${ }^{6}$ e de colheita ${ }^{7}$ das frutas, os empregos ofertados são temporários e obedecem a contratos que variam de 15 a 45 dias, comumente.

No Parque de Industrialização - também conhecido por packinghouse - são realizadas as atividades de pós-colheita, como o armazenamento do fruto que chega do pomar em câmaras frigoríficas, sua classificação em categorias de qualidade, sua embalagem e sua comercialização. Os empregos ofertados por essa atividade industrial são permanentes, havendo contratação de temporários em momentos de maior pico, mas em menor número. A figura abaixo demonstra os espaços pertinentes ao pomar e ao parque de industrialização

\footnotetext{
${ }^{6} \mathrm{O}$ raleio da fruta diz respeito à retirada de frutos excedentes do galho em uma fase anterior à colheita, quando eles ainda estão nascendo. $\mathrm{O}$ objetivo dessa tarefa é garantir que as frutas que permaneceram no pé tenham espaço e incidência de luz solar para se desenvolverem. Durante a pesquisa de campo, era muito comum os produtores afirmarem que realizavam o raleio químico. No entanto, pude observar que trabalhadores indígenas são contratados para realizar o raleio, que acontece nos meses de outubro a novembro.

${ }^{7}$ A colheita da cultivar Gala acontece no final do mês de janeiro e pode se estender até início do mês de março. Já a colheita da cultivar Fuji ocorre cerca de 15 dias depois. A Gala é majoritária nos pomares e necessita de uma colheita rápida, pois pode começar a cair do pé e inviabilizar sua comercialização in natura. É comum que os produtores finalizem o contrato dos trabalhadores com o fim da colheita da Gala e recontratem novos para a colheita da Fuji. A preocupação dos produtores está em pagar somente os dias necessários para o trabalho, como apontou Graziano Silva (1981).
} 


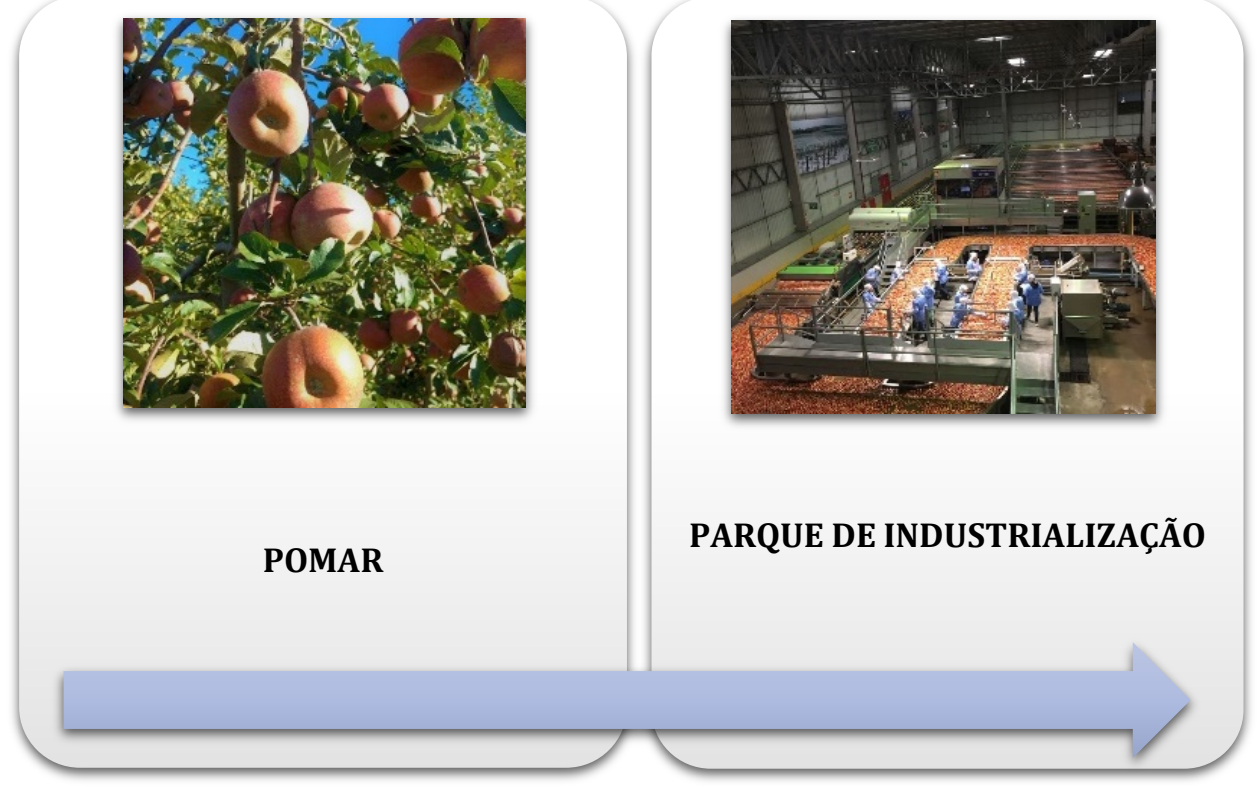

Figura 1:Pomar e parque de industrialização de maçãs. Elaborado pela autora, 2019.

Dentro desse processo produtivo, os trabalhadores indígenas são contratados para os trabalhos temporários no pomar - para o raleio e para a colheita - juntamente com outros perfis de trabalhadores. É interessante notar que os trabalhadores e trabalhadoras são sempre classificados pelos produtores de maçã, que não consideram seus marcadores de diferença cultural. Dessa forma, os trabalhadores são classificados, por exemplo, em "haitianos", "nordestinos", "trabalhadores da laranja", "os da fronteira" e "os índio". No ponto de vista do capital, existem perfis de trabalhadores para quem o sentido do trabalho pode contribuir com sua valorização - quando o trabalhador se autoexplora no emprego - ou contribuir para sua depreciação - quando o sujeito restringe seu esforço à meta estabelecida pelo produtor. Um produtor, descendente de imigrantes italianos, expressa sua leitura sobre o que significa trabalho para os indígenas

Uma vez eu fui num pomar do Ivo. Estranhei. Um dia de sol bonito, em plena
colheita, e a gente estava atrasado. Três da tarde. Eu te digo: os caras estavam
em traje de missa! De passeio, viu? Tomando chimarrão. Eu digo: "eu não
acredito. O que é isso aí? Esses caras, o que aconteceu? De banho tomado e
tal"? Ele [o Ivo] disse: "não, não, eles atingiram os três bins deles. E, se nós
forçarmos, ele vai embora. Ele vai embora". Então, tem dia para colher mais
um bin e meio, dois, tranquilo (Leonel, descendentes de imigrantes italianos,
pequeno produtor, 2018).

Para o produtor Leonel, o tempo significa oportunidade para aumentar a produção, mesmo que haja um mínimo de colheita por trabalhador pré-estabelecido e 
que os indígenas já tivessem cumprido o acordo. Cada etnia assume diferentes posicionamentos diante do fato de estarem somando a identidade de um assalariado rural. Nem todos agem com o mesmo propósito de lucrar com sua mercadoria denominada força de trabalho. A tendência é que os trabalhadores de variadas culturas sejam vistos como homogêneos pelo capital ${ }^{8}$. Todavia, neste artigo, focalizei a migração e a contratação de trabalhadores indígenas, cuja atuação tem se tornado cada vez mais frequente nos pomares de maçã de Vacaria.

\section{A migração e contratação de trabalhadores indígenas}

A migração de trabalhadores para os pomares de maçã em Vacaria é um processo altamente controlado por instituições do Estado. Esse controle se consolidou a partir do momento em que passou a decidir quem poderá migrar e permanecer no trabalho, além de garantir que quem migrou retorne para seu local de origem.

Os serviços públicos de segurança do município de Vacaria realizam um controle a respeito do quantitativo de trabalhadores que vão para as atividades de colheita de maçã. Esse controle denomina-se "operação colheita”, em que cada produtor deverá entregar o nome e o número de identificação de cada trabalhador temporário aos agentes de segurança pública A partir disso, gera-se uma lista de trabalhadores que serão consultados em um sistema eletrônico, capaz de identificar aqueles que possuem alguma pendência com o sistema jurídico. Embora essa lista exista com o objetivo de rastrear sujeitos considerados foragidos da justiça que poderiam estar entre - ou até mesmo ser - os trabalhadores, ela consegue dar uma dimensão do número de pessoas empregadas durante o período de colheita. Graças a essa lista, é possível saber que cerca de 12 a 15 mil trabalhadores são contratados temporariamente para o período da safra somente em Vacaria. Conforme entrevista com servidor público que atua diretamente nessa operação,

Porque dentro desses 15 mil [trabalhadores], tem as pessoas que realmente vêm trabalhar, que vêm levar dinheiro para casa, que está complicado de situação. Mas tem outros, que às vezes vem pra cá pra fugir. (...) Existe um banco de dados nacional, que é o Banco Nacional de Mandatos de Prisão, que temos acesso pelo nome da pessoa e pela filiação, a qualquer tribunal de justiça do Brasil. Então

\footnotetext{
${ }^{8}$ As escolhas teóricas e metodológicas que serviram para atingir o objetivo desta pesquisa não possibilitaram a exploração do sentido do trabalho para cada grupo étnico, a partir de suas cosmologias.
} 
conseguimos ver, se o cara é lá do Acre, e está foragido, a gente consegue encontrar, aqui no pomar digamos. Durante esses anos da operação colheita, no primeiro ano, como eu estava te dizendo, dentre essas 10 mil, 15 mil pessoas que vieram de fora, nós encontramos 69 foragidos (Carlos, servidor público, 2018).

O entendimento deste servidor público do setor de segurança pública do município de Vacaria a respeito dos trabalhadores temporários é de que existe uma oportunidade de esconderijo para quem está com alguma pendência com a justiça. Em um relato de um produtor, ele menciona que autoridades da justiça visitaram seu pomar a fim de conduzir até a delegacia um suposto foragido que estava entre seus trabalhadores. Segundo o trabalhador, ele já havia cumprido a pena de sua condenação, mas, por algum motivo, seu nome constava nos registros policiais do Acre.

Evidentemente, essa situação demonstra a existência de uma dicotomia, na qual o oposto de "trabalhador" é "foragido", e este é impedido de trabalhar diante do controle que o Estado exerce no mercado de trabalho.

Com o tempo, as instituições do Estado fixaram normas sobre como deveria ocorrer o processo de deslocamento dos trabalhadores. A Norma Regulamentadora - 31 (NR-31), que trata da saúde e da segurança no trabalho realizado nos setores da agricultura, da pecuária, da silvicultura, da exploração florestal e da aquicultura, determinou que as contratações dos trabalhadores deveriam acontecer no local de origem e que os empregadores tinham a responsabilidade de reconduzir esses trabalhadores ao seu local de origem ao final da safra.

No que se refere aos trabalhadores indígenas, a Norma Regulamentadora - 31 é responsável pela configuração dos deslocamentos desses povos aos pomares de maçã em Vacaria em um esquema complexo, que envolve velhas práticas combinadas com as normas legais que eu pretendo esmiuçar ao longo deste artigo.

Neste contexto, a maioria desses trabalhadores indígenas pertencem majoritariamente a três etnias. Em minha pesquisa de campo, consegui localizar trabalhadores em seus locais de origem, por meio do método de amostragem em cadeia por referência. Algumas instituições consultadas durante o trabalho de campo tinham certo conhecimento destas contratações, mas não possuíam maiores detalhes. Um exemplo foram as situações que envolviam a FUNAI. Em algumas sedes, os servidores afirmavam que as relações de contratação e migração não passavam por eles. Em outras sedes, os servidores envolviam-se mais, principalmente nos casos de violação dos direitos trabalhistas, mas suas ações estavam restritas a visitar o local de trabalho e 
conversar com os produtores sobre as especificidades das etnias contratadas ou, às vezes, à realização de denúncias ao (extinto) Ministério do Trabalho e Emprego (MTE) e ao Ministério Público do Trabalho (MPT).

Os jornais de alta circulação do estado gaúcho passaram a veicular notícias a respeito do fenômeno migratório aparentemente recente. Destaco uma publicação do jornal Zero Hora que, além de noticiar o fato, concede ao leitor uma explicação sobre a justificativa da contratação de indígenas, que seria para "ajudara suprir a falta de mão de obra na safra":

\title{
Menu $\quad$ CapazH $\quad$ Campo e Lavoura \\ Fruticultura \\ Índios viajam de Mato Grosso do Sul a Vacaria para trabalhar na colheita da maçã
}

\author{
Migração ajuda a suprir falta de mão de obra para safra, que atrai mais de 15 mil pessoas de fora da cidade \\ Por: Joana Colussi, Vacaria \\ 1002/2015-05no1min

Figura 2:Jornal Zero Hora sobre deslocamento de trabalhadores do MS para o RS, $2015^{9}$.

A literatura sobre o deslocamento de trabalhadores em busca de trabalho demonstra como a migração é um fenômeno complexo e heterogêneo. Comumente, a migração está associada aos camponeses expropriados que procuram por trabalhos em outros lugares, a fim de garantir sua reprodução social. Este aspecto social da migração pode ser observado nos estudos de Bendini, Steimbreger e Radonich (2011) e Steimbreger, Trpin e Bendini (2011) sobre o deslocamento de trabalhadores migrantes sazonais da produção de peras e maçãs na Argentina, de Silva $(1999,2004)$ sobre o fenômeno migratório de trabalhadores da cana-de-açúcar, de Graziano Silva (1981) sobre a formação dos trabalhadores "boias frias" na produção de cana-de-açúcar e de Menezes (2002) sobre o trabalho de paraibanos e pernambucanos na produção canavieira.

\footnotetext{
${ }^{9}$ Disponível em: <http://zh.clicrbs.com.br/rs/noticias/campo-e-lavoura/noticia/2015/02/indios-viajam-demato-grosso-do-sul-a-vacaria-para-trabalhar-na-colheita-da-maca-4697016.html $>$. Acesso em: 09 jun 2019. Outra matéria de capa foi veiculada por este mesmo jornal mais recentemente, tendo como título "As tribos que colhem a maçã", em que destacavam o crescente número de indígenas trabalhando nos pomares de Vacaria (Zero Hora, 15 e 16 de fevereiro, ano 56, $\mathrm{n}^{\circ}$ 19, Porto Alegre, 2020).
} 
Nesse sentido, Graziano Silva (1981) demonstra que o processo de expropriação de camponeses na região de São Paulo está relacionado à mecanização da agricultura nos anos 1970. Tendo como pano de fundo as políticas de modernização da agricultura do regime militar, Graziano Silva (1981) esmiúça a intensificação no número de trabalhadores volantes naquela região. De uma maneira muito mais detalhada, Silva (1999) descreve os mecanismos de grilagem das empresas de celulose na região do Vale do Jequitinhonha, demonstrando, por meio de um exímio trabalho de campo, como posseiros tiveram seus territórios tomados por intermédio legal. Em seu trabalho, fica evidente a migração desses trabalhadores para as fazendas de cana-de-açúcar na região de São Paulo, com especial destaque aos intermediários da relação capital/trabalho, que Silva (2004) aponta como uma relação social bastante antiga.

Os trabalhos de Bendini, Steimbreger e Radonich (2011) e Steimbreger, Trpin e Bendini (2011) debruçam-se sobre os migrantes sazonais do setor frutícola, especialmente a produção de maçãs. Esses trabalhos demonstram a situação de intermediação enfrentada pelos colhedores, denunciando a presença das falsas cooperativas que superexploram os trabalhadores, suprimindo seus direitos trabalhistas - algo muito comum na contratação de indígenas para os pomares de Vacaria no final da década de 1990.

No trabalho de Menezes (2002), fica evidente a coexistência de intermediários conhecidos por "arregimentadores" e "empreiteiros", em que os primeiros se destacam por formalizar a relação de trabalho dos sujeitos que são levados para trabalhar, diferentemente dos segundos, que não formalizam o vínculo empregatício junto aos empregadores. No caso da produção de maçãs, o "recrutador" é o intermediário que assume características semelhantes às do arregimentador. Por ser responsável pelo recrutamento e registro do vínculo empregatício dos trabalhadores, o recrutador acaba sendo um funcionário da empresa que produz maçãs e dedica suas atividades somente a ela, enquanto o empreiteiro se responsabiliza somente por recrutar trabalhadores e conduzi-los até o pomar, podendo atender às necessidades de mais de um produtor.

Esses indígenas, que atualmente trabalham na colheita da maçã e que saem do estado do MS, já são velhos conhecidos das atividades de colheita da cana-de-açúcar. A mecanização da colheita da cana, na década de 1990, reduziu o emprego desse perfil de mão de obra, que passou a enfrentar distâncias maiores para conseguir trabalhar. Conforme um trabalhador indígena que trabalhava na colheita da cana-de-açúcar e passou a colher maçãs, 
Antes aqui, da gente.., por exemplo, de eu te uma formação, aqui era tudo bem complicado, né? Pra saí da minha aldeia, lá, por exemplo, eu tinha que sair umas duas semanas até chegar aqui. É muito longe, é mata, né? Era só de cavalo, de carreta de boi. (...) o trabalho que era aqui era o corte de cana, nessas usina, tudo aí pra baixo, até berada de São Paulo é... tudo trabalho indígena. E era mais isso. (...) Surgiu máquina e ficou sucateando os povos indígena. (...) Aí eu voltei, comecei estudar né? (...) Aí esses tempo atrais que nós fomo pra maçã. Surgiu a oportunidade... eu falei "eu vou lá conhecer"... eu queria ver pé de maçã... eu cheguei lá, só de olhar, eu enjoei [risos] é muita maçã. (...) Como os indígena são muito, não sai tudo. Sai um poco. Aí foi, nóis chegamo lá, eu falei "vamo conhece, porque não tinha mais cana" (Juliano, indígena, trabalhador, 2018).

Entretanto, no caso dos trabalhadores indígenas do MS que trabalham na colheita da maçã em Vacaria, a migração parte da empresa que "busca" por esse perfil específico. Atualmente, as negociações são realizadas na terra indígena entre o representante da empresa contratante e uma liderança indígena - geralmente o cacique e não diretamente com os indígenas que serão contratados. O representante da empresa, quando é um funcionário, denomina-se "recrutador", porém reconhece-se como "empreiteiro" quando é terceirizado. A liderança indígena que vai intermediar as relações entre os trabalhadores indígenas e o recrutador da empresa é comumente conhecido por "cabeçante". Em algumas terras indígenas, ele pode ser o cacique ou o representante da aldeia.

Comumente, o recrutador chega até a terra indígena e apresenta a proposta de trabalho para o cacique. Depois da autorização do cacique, o cabeçante organiza as turmas de trabalhadores. Cada trabalhador deverá entregar sua documentação civil inclusive carteira de trabalho - para o cabeçante, que vai repassar ao recrutador. $\mathrm{O}$ recrutador organiza a documentação referente ao contrato de trabalho dessas pessoas desde seu deslocamento até a empresa, como demanda a Norma Regulamentadora $31^{10}$. Depois disso, conduz os trabalhadores até o município de Vacaria. Chegando ao local de trabalho, os trabalhadores ficam em alojamentos durante o período contratado e são chefiados por seus líderes cabeçantes.

Os alojamentos são dormitórios construídos, também, de acordo com as instruções da Norma Regulamentadora - 31 e estão localizados dentro do pomar. Ao chegar ao pomar, os trabalhadores são alojados nesses espaços, onde permanecerão durante o período da safra, que pode durar de 15 a 45 dias, comumente. Durante a

\footnotetext{
${ }^{10}$ Trata-se da portaria $\mathrm{n}^{\mathrm{o}} 86$ do Ministério do Trabalho e emprego, datada de 2005 , que versa sobre segurança e saúde no trabalho na agricultura, pecuária silvicultura, exploração florestal e aquicultura.
} 
pesquisa de campo, alguns trabalhadores indígenas mencionaram o fato de que o cacique teve que buscar os trabalhadores que desistiram do emprego e que não tiveram condições materiais para retornar ao local de origem. Em outros depoimentos, mencionaram indígenas do Mato Grosso do Sul que estavam à beira das rodovias tentando alguma carona de volta para casa, depois de desistir do trabalho. Em contrapartida, os produtores apontavam que, nos casos de desistência do trabalhador, o produtor pagava as passagens de ônibus para que o trabalhador pudesse retornar para casa.

No pomar, o cotidiano dos trabalhadores era guiado pelo horário de trabalho, com intervalo para café, almoço e jantar. Durante a noite, no período de não trabalho, alguns alojamentos possuíam regras mais rígidas quando comparados com os alojamentos de outros pomares. Segundo a experiência de um trabalhador indígena,

Eu fui em pomares que a coisa era meio que largado, sabe? Não tinha segurança, alimentação, ela era um lugar não apropriado, sabe? A higiene era muito... precária. Mas eu também fui em pomares - agora, nesses últimos anos aqui - nós tinha segurança, a higiene era boa, né? A gente tinha horário para dormir, né? Isso facilitava muito o nosso trabalho, também. Porque, com barulho, a gente não descansa pro outro dia. E esses últimos ano que eu trabalhei foi muito bom. Assim, pra sair para fora, do pomar, tinha que ter autorização, explicar por que tava saindo, né? Era uma segurança pra nós, trabalhador, também, né? Mas, em compensação, a gente foi em pomares que... era... liberado. Cada um fazia o melhor que achava pra si. [...]. Porque... queira ou não queira, são tudo nossos parente. Geralmente, a gente ficava no mesmo quarto. Aí, alguém saía, tomava umas e passava do limite, nesses lugares, né. E aí, tu não descansava. [...]. Tem uns pomares aí... principalmente o Naranja e o Frutilla, né? Ali a coisa era largada, sabe? Cada um fazia o que achava melhor, bebia... usava droga... e a gente que não participava disso, ficava meio que com medo, sabe? (Getúlio, indígena, trabalhador, 2018).

Nesse contexto, o cabeçante é quem lidera a organização do pomar, intermediando as relações entre os trabalhadores indígenas e os produtores de maçã. Para um presidente de Sindicato de Trabalhadores Rurais, a figura do cabeçante é bastante prejudicial aos trabalhadores, pois eles podem estar comprometidos com os interesses da empresa e confundir os trabalhadores a respeito dos seus direitos,

O cabeçante da questão da cana, eles são muito... é muito relativo. Eles são muitos amigo: patrão e cabeçante. Eu até fiz umas reunião com o pessoal aí dessas duas aldeias, Nascer do Sol e Pôr do Sol, e eu sempre falo. Sempre sou questionado por algum, alguma pessoa que você vê que tá bem trajada. [A] posição dele, que é liderança, é... cabeçante, né? Então eles fala assim ó "Sindicato atrapalhou... acabou o corte da cana". Não foi o Sindicato, é meio ambiente. Não pode queimá. O trabalhador, na verdade, ele gosta do sindicato. Agora, os cabeçante não gosta muito não. Não gostam porque são muito parcero do... das empresa. Porque eles ganham mais do que os outro, né? Apesar de que eles têm responsabilidade também. (...) A 
gente sabe, não vou falar nome, sabe que existe esquema, que o cara vê pra pagá primeiro. Conversa com capitão, com cabeçante. Então, essa forma, eu acho estranho. Por que não chega direto [nos trabalhadores]? (Mauro, branco, presidente de um Sindicato de Trabalhadores Rurais 2018).

Os cabeçantes são conhecidos por organizar turmas de trabalhadores para trabalhar não só na colheita de maçãs, mas também na colheita do alho, da batata, da cebola e em alguns serviços de frigoríficos. No caso da maçã, os cabeçantes recebem um salário de trabalhador rural acrescido de um valor correspondente à produtividade do trabalhador indígena. Comumente, o controle de preenchimento do bin é realizado pelo monitor do pomar, que é um trabalhador permanente da empresa, muito embora os trabalhadores indígenas façam seus próprios cálculos. De modo geral, os monitores dividem o número de bins colhido pelo número de integrantes da equipe. Se o número de bins ultrapassar a meta de colheita diária, cada integrante passa a receber um valor além do salário, correspondente ao "bônus de produtividade".

O "bônus de produtividade" é pago aos trabalhadores e diz respeito a uma retribuição, separada do salário, pela superação da meta de frutas colhidas no dia. O salário é condicionado ao cumprimento da meta, que gira em torno de 2,5 bins (ou 875 quilos de maçãs). Quando o trabalhador supera essa marca, passa a receber um valor por bin ( $R$ \$ 25 reais em 2018), mas parte desse valor ( $\mathrm{R} \$ 5,00)$ vai para o cabeçante. Em outras palavras, parte do pagamento do trabalhador vai para o intermediário cabeçante, mas, aos olhos da legalidade, não se trata do salário, mas de um "bônus". Uma liderança indígena mencionou sua reprovação a esse tipo de desconto, pois entende que esses ganhos são únicos e exclusivos dos trabalhadores. Além disso, apontou que as negociações antes da contratação envolvem o pagamento de uma "taxa comunitária", que é um valor pago pelo recrutador per capita à liderança do lugar e, assim, poder acessar os trabalhadores dos quais precisa. De acordo com sua fala,

por que que o estado [RS] ultrapassou outro estado [MS] para poder pegar esse trabalhador? Alguma coisa já tá errado aí. Por que não pega o trabalhador mesmo do seu estado mesmo e ter colocado na colheita de maçã? Essa é uma grande pergunta. Segundo, a partir da... de levar o trabalhador lá pra colheita, muita gente falaram que sofreram bastante. Sofreram muito porque não tinha noção como é que era a colheita da maçã. E o segundo ponto, quando você coloca cabeçante e o que vai pra lá, no primeiro momento, que funciona desse sentido: se eu vô levá 40 pessoa, a empresa paga por essa pessoa 8 reais pra liderança. Entendeu? [...]. Então, a liderança, que a gente chama de taxa comunitária, ganharia 320. Então, ser capitão da aldeia é lucro, é vantagem pra você, que vai pegar esse dinheiro. Segundo momento, a do cabeçante, ele vai se encarregar daquele quadro de 39 pessoa no trabalho. Então, o 
cabeçante tem o benefício em cima do trabalhador com a empresa. Como isso funciona, eu não sei [...] (Breno, liderança indígena e política, 2018).

As migrações e as formas de contratação dos trabalhadores temporários se interligam. No caso da produção de maçãs em Vacaria, as formas de contratação dos indígenas são semelhantes às da cana-de-açúcar, principalmente por permanecer agora, dentro da lei - a figura controversa do intermediário das relações entre capital e trabalho. Na literatura especializada, ele aparece como "gato" (Silva, 1999), “arregimentador" e "empreiteiro" (Menezes, 2002). No caso da maçã, os intermediários são conhecidos por "empreiteiro", "recrutador" e "cabeçante".

Durante a pesquisa de campo, consegui observar que as contratações de indígenas já aconteciam, principalmente para as atividades de raleio da fruta, mas estava restrita aos indígenas do Sul do Brasil. É interessante observar que, no início da década de 2000, esses indígenas eram buscados em seu local de origem por empreiteiros ou falsas cooperativas. Os empreiteiros não eram funcionários da empresa, mas elas os procuravam e pediam um número específico de trabalhadores. A função do empreiteiro era buscar essas pessoas no seu local de origem e conduzi-las até Vacaria. Diversas situações ocorreram nesse período. Um indígena que experienciou esta época contou como acontecia a contratação:

Com meus dezesseis anos, né?, a pessoa que nos levava pra trabalhá, não precisava a gente apresentar documento nenhum (...) Era só... Era só dá o teu nome. (...) A pessoa te levava pra trabalhá. A agente ficava trinta... quarenta, quarenta e cinco dia, sessenta dia até, trabalhando. Até o final da colheita. (...) Porque, né?, a gente chegava e a pessoa que nos levava nos colocava num barraco, numa casa assim, tudo aberto, né? Não tinha repartição de quartos, não tinha. Os colchão que a gente ganhava não era esses colchão alto, era colchão baixo... Nem era colchão, vamo dizê assim. (Carlos, indígena, trabalhador, 2017).

Depois de 2005, com a NR-31, os trabalhadores deveriam sair de seu local de origem com a carteira assinada, pois já seriam trabalhadores empregados pela empresa. Os empreiteiros deveriam representar a empresa e realizar esse contrato. Segundo uma empreiteira, as contratações aconteciam mais ou menos desta maneira

A gente saiu com o contrato de lá. [Eram] 45 dias. Chegou aqui [em Vacaria], o contrato era de 15 dias... Até que o pessoal entendeu, quando ele [o empresário] fez a reunião, explicou que era norma da empresa... Todo mundo assinou, só um rapaz não assinou. Só que, em vez dele chegar pra mim e dizer "Raquel, o fulano [trabalhador] tá dando problema", não. Olha o que ele [empresário] fez: o rapaz foi lá no escritório, rasgou o contrato, jogou na cara dele. Quando foi de tarde, ele disse assim pra mim "ô Raquel, a gente achou melhor dispensar o pessoal". Por um, 
menina! Tu acredita? Por um! Aí, dispensou todo mundo. Por isso, eu acho que eles estão apostando né, que nem dizem na... Nos índio, que geralmente índio não tem estudo, é ignorante [a respeito dos direitos trabalhistas], a maioria. (Raquel, parda, safrista, empreiteira, 2018).

A empreiteira Raquel percebeu que havia algo nos trabalhadores indígenas que os diferenciava dos não indígenas e que isso tinha relação com a forma com que eles reagem às transgressões dos direitos trabalhistas. E, por este motivo, estariam sendo preferidos nas contratações dos produtores.

Além do empreiteiro, no início do século XXI era muito comum as atuações de falsas cooperativas de trabalho, onde o trabalhador se "associava" como um "cooperado" e estimava receber um certo valor por semana de trabalho. A suposta cooperativa não tinha sede física e, quando havia desistência do trabalhador, seu pagamento ocorria em uma cidade diferente de Vacaria, onde estaria a sede. A transcrição abaixo se refere ao direito de resposta de uma cooperativa, concedida pela Rádio local. No dia anterior, trabalhadores foram até a emissora de rádio para denunciar as práticas da falsa cooperativa.

Cooperativa: a gente não faz um contrato, é um termo de compromisso que eles assinam com nós, de cumprir trinta dias de serviço. [...]. Bateu a saudade que bate em qualquer um. "Eu quero ir embora". Aí eu pego e faço o recibo de retirada como cooperante da cooperativa, porque ele não é folha de pagamento. (Responsável por cooperativa de trabalho em entrevista divulgada em emissora de rádio local, 2001).

Era muito comum essas cooperativas se apresentarem com endereços nos arredores das terras indígenas, nos municípios vizinhos, e se valerem dessa força de trabalho.

Dentro da NR-31, o retorno dos trabalhadores para seu local de origem também é atribuição da empresa, mesmo quando há desistência do contrato de trabalho pelo trabalhador. Neste caso, as empresas deverão custear seu retorno para casa. Todavia, durante o trabalho de campo, tive depoimentos de indígenas que saíram do emprego e estavam desamparados em Vacaria, como mencionei anteriormente.

Essas migrações e contratações de trabalhadores indígenas se preocupam com seu traço de legalidade, com a presença de uma carteira assinada, contratos e pagamentos combinados. No entanto, velhas práticas que envolvem a chegada do estranho (Martins, 1993) permanecem e podem se reproduzir dentro da legalidade. O recrutador, que é um intermediário das relações entre capital e trabalho, pretendeu se 
afastar dos traços depreciativos que existiam com o empreiteiro e com o "gato". Esses traços depreciativos da função se popularizaram com as formas de trabalho como a servidão por dívida (Silva, 2004).

\section{Considerações finais}

Este artigo tem como objetivo analisar as migrações de assalariados indígenas que trabalham temporariamente nas colheitas de maçã no Sul do país, mais precisamente nos pomares do município de Vacaria/RS, com o intuito de compreender como elas estão atreladas à produção de capital por meio da economia do agronegócio. Trata-se de um fenômeno relativamente recente na região, pois a contratação de indígenas para as atividades de raleio e de colheita se intensificou na década de 2000.

Os indígenas eram contratados para a realização de atividades no pomar, como o raleio e a colheita das frutas, que tem duração de poucos meses de trabalho. Devido os tensionamentos da relação de produção entre o capital e o trabalho, as instituições do Estado passaram a controlar o mercado de trabalho, definindo quem está ou não apto a migrar.

Nesse sentido, os empregos ofertados pelo agronegócio, especialmente na produção de maçãs, possuem características formais, em que os contratos de trabalho são registrados nas carteiras de trabalho. Nessa relação, os indígenas recebem uma outra identidade para somar com a sua especificidade étnica: a de trabalhadores assalariados rurais.

Todavia, trata-se de um emprego formal e precário, ao mesmo tempo, por ser temporário e pago somente os dias trabalhados. Ainda, os períodos de contrato são curtos e este trabalho não se responsabiliza pela reprodução social desses trabalhadores nos períodos de não trabalho.

Quando o trabalhador desiste de trabalhar no pomar há perda de capital, uma vez que se realiza um cálculo racional da mão de obra disponível para realizar a colheita da maçã no período estimado. Talvez a distância do local de moradia e do local de trabalho seja benéfico no ponto de vista do capital. Além disso, a contratação de um número grande de trabalhadores por meio de apenas um - o cabeçante - é capaz de reduzir o tempo de contratações ou, até mesmo, do ensinamento de como o trabalho deve ser realizado no pomar. 
Mesmo havendo forte controle do Estado a respeito das contratações, é importante notar que as figuras controversas dos intermediários ainda persistem coexistindo com as formas mais formalizadas. O líder cabeçante, que recebe parte do bônus conquistado pelos trabalhadores em seu trabalho, exerce um papel político importante no que diz respeito à identidade de trabalhadores rurais.

Assim sendo, há de se pensar muito mais sobre esses deslocamentos, que parecem se diferenciar das lógicas mais tradicionais camponesas de migração por trabalho. Aqui, o Estado exerce forte controle sobre o mercado de trabalho e dos trabalhadores aptos a executar este trabalho. Evidentemente, esta investigação continua e muitas outras podem ser agregadas para se pensar a divisão racial do trabalho na sociedade em torno do agronegócio.

\section{REFERÊNCIAS}

ACOSTA, Alberto; BRAND, Ulrich. Pós-extrativismo e decrescimento: saídas do labirinto capitalista. São Paulo: Elefante, 2018.

BECKER, Howard Saul. Outsiders: estudos de sociologia do desvio. Rio de Janeiro: Zahar, 2008.

BENDINI, Mónica; STEIMBREGER Norma Graciela; RADONICH, Martha. "He andado por la vida y me he golpeado": memoria de périplos y condiciones migratorias de cosecheros agrícolas. Ruris, v. 5 n. 1, p. 13-48, 2011.

BENDINI, Mónica; STEIMBREGER Norma Graciela; TRPIN, Verónica. Trabajadores agrarios migrantes: características y funciones de la intermediación laboral em los mercados de trabajo agrario temporario. Buenos Aires: Universidade Nacional de Comahue, Facultad de Derecho y Ciencias Sociales, 2011. 111p. (Relatório PROINDER, 31).

BIERNARCKI, Patrick.; WALDORF, Dan. Snowball sampling-problems and techniques of chain referral sampling. SociologicalMethodsandResearch, v.10 p. 141$163,1981$.

CARDANO, Mario. Manual de pesquisa qualitativa: contribuição da teoria da argumentação. Petrópolis: Vozes, 2017.

DAVIS, John Hebert; GOLDBERG, Ray. A concept of agribusiness. Division of research graduate school of business administation. Harvard university Boston: The Alpine press inc., 1957. 
DELGADO, Guilherme. A questão agrária hoje. In: MATTEI, Lauro. (Org.). Reforma agrária no Brasil: trajetória e dilemas. Florianópolis: Insular, 2017.

. Do "capital financeiro na agricultura" à economia do agronegócio: mudanças cíclicas em meio século (1965-2012). Porto Alegre: Editora da UFRGS, 2012.

GIL, Antônio Carlos. Métodos e técnicas de pesquisa social. $6^{a}$ edição. São Paulo: Editora Atlas S.A., 2008.

KLANOVICZ, Jó. Natureza Corrigida: uma história ambiental dos pomares de macieira no sul do Brasil (1960-1990). 2007. 311f. Tese (Doutorado em História) Centro de Filosofia e Ciências Humanas, Programa de Pós-Graduação em História, Universidade Federal de Santa Catarina, Florianópolis, 2007.

MARTINS, José de Souza. A chegada do estranho. São Paulo: Haucitec, 1993.

MAZON, Márcia da Silva; SILVA, Leonardo. Produzir maçãs, construir sentidos: gênese da pomicultura no sul do Brasil. Estudos de Sociologia, Araraquara, v. 22, n 43, p. 299-319, 2017.

MENEZES, Marilda Aparecida de. Redes e enredos nas trilhas dos migrantes: um estudo de famílias camponeses-migrantes. Rio de Janeiro: RelumeDumará; João Pessoa: EDUFPB, 2002.

POLANYI, Karl. A grande transformação:as origens da nossa época. $2^{\mathrm{a}}$ edição. Rio de Janeiro: Campus, 2000.

SILVA, José Graziano da. Progresso técnico e relações de trabalho na agricultura. São Paulo: Editora Haucitec, 1981.

SILVA, Maria Aparecida de Moraes. A luta pela terra: experiência e memória. São Paulo: UNESP, 2004.

. Errantes do fim do século. São Paulo: Fundação da Editora da Unesp, 1999.

TAYLOR, Marcus; RIOUX Sébastien. Global labour studies. Cambridge: Polity Press, 2018.

VINUTO, Juliana. A amostragem em bola de neve na pesquisa qualitativa: um debate em aberto. Temáticas,Campinas, v. 22, n. 44, p. 203-220, 2014.

Recebido 07/04/2020

Aprovado 10/04/2020 